\title{
Perioperative control of blood glucose
}

\author{
Serife Mehlika Kuskonmaz ${ }^{1}$, Mustafa Arslan ${ }^{2}$
}

\begin{abstract}
This review mainly focuses on the management of type 2 diabetes in the preoperative setting with a special emphasis on intraoperative glycemic control. Some patients learn their diagnosis of diabetes just prior to the surgery. The prevalence of previously undiagnosed diabetes is reported to be $5.2-10 \%$ in literature. Treatment protocols must be tailored individually but evidence based approach in insulin administration and close monitoring of blood glucose are important in order to avoid both hyper and hypoglycemia
\end{abstract}

Key words: Diabetes Mellitus, Perioperative hyperglycemia, Preoperative care

\section{Introduction}

Prevalence of diabetes is increasing worldwide (1). Management of diabetes in the perioperative setting is a challenge to physician. There are many different treatment protocols applied and yet the target glucose value is a matter of debate among practicing doctors. So, regular, updated and evidence based renewal of data is necessary in the field. This review mainly focuses on the management of type 2 diabetes in the preoperative setting with a special emphasis on intraoperative glycemic control.

\section{Perioperative hyperglycemia vs diabetes mellitus}

Before going further with the perioperative management of diabetes, it is appropriate to explain the term: "perioperative hyperglycemia". This term refers to the hyperglycemia in surgical patients who are known to be non-diabetic (2). Hyperglycemia due to surgical stress is a result of a couple of metabolic changes in glucose utilization including release of counter-regulatory hormones and pro-inflammatory cytokines. Like diabetes, perioperative hyperglycemia is associated with adverse outcomes after surgery. Increased incidence of infections and increased mortality is reported in patients with perioperative hyperglycemia (3-5). Perioperative hyperglycemia is assumed to be associated with the degree of severity of the related stress. Further studies are needed to clarify if perioperative hyperglycemia directly contributes to the adverse outcomes and if its management prevents perioperative morbidities.

\section{Hyperglycemia and perioperative adverse events}

Association between hyperglycemia and variable perioperative risks is well defined (6). Clinical studies showed increased morbidity and mortality with hyperglycemia, after coronary artery bypass grafting (7-8). Diabetes is a well-known risk factor for postoperative infections (9), acute renal failure, ileus and prolonged hospital stay (10-11). These data show the importance of perioperative blood glucose control in diabetes. Current guidelines do not recommend routine preoperative screening for diabetes (12). Criteria for diabetes screening in general population are defined by American Diabetes Association (ADA). ADA suggests screening for all adults who are 45 years or older and for younger adults whose body mass index $>25 \mathrm{~kg} / \mathrm{m}^{2}$ and have at least one additional risk factor. These risk factors are summarized in the table 1 (13).

Table 1. Summary of risk factors for diabetes

Physical inactivity
First degree relative with diabetes
High risk ethnicity
History of gestational diabetes
Hypertension
Dyslipidemia
Polycystic ovary syndrome
History of prediabetes
Conditions associated with insulin resistance (obesity,
acanthosis nigricans)
Cardiovascular disease

\section{Preoperative care of the diabetic patient}

Some patients learn their diagnosis of diabetes just prior to the surgery. The prevalence of previously undiagnosed diabetes is reported to be 5.2-10\% in literature $(14,15)$. These patients seem to have a higher risk of perioperative mortality when compared to patients who are aware of their diabetes (16). 
Poor glycemic control is an established risk factor for perioperative morbidity. $\mathrm{HbA} 1 \mathrm{c}$ is shown to be correlated with the risk. However it is not known whether surgery should be postponed until a better HbA1c value is achieved or not $(17,18)$. It is difficult to estimate the real contribution of diabetes to perioperative morbidity since many diabetic patients have confounding factors like obesity or smoking history (19).

While preparing a diabetic patient to surgery, it is essential to take a detailed history of diabetes and its complications with a thorough list of medications. Guidelines advise prioritizing diabetic patient on the operating list (20). In general, it is suggested to continue the usual oral anti-diabetic medications until the day of surgery $(21,22)$. Some oral anti-diabetics have specific effects so should be withheld at least 24 hours before surgery. Sulfonylureas are one of them. Sulfonylureas preclude the cardiac protection mechanism named "ischemic preconditioning" by closing the ATP dependent potassium channels (23). Metformin is supposed to increase the risk of lactic acidosis especially when renal dysfunction is present. So metformin is also stopped $24-48$ hours before surgery. (24).

Dose adjustment is needed for patients who are already on insulin. Some authors suggest halving the dose of long acting insulin on the morning of surgery and changing the premixed insulin- which contains both short acting and intermediate acting insulin -to NPH insulin for that morning $(25,26)$. If proper glycemic control is not achieved in a patient who is on oral anti-diabetics, basal-bolus insulin regimen is appropriate. In a study, $0.4-0.5 \mathrm{U} / \mathrm{kg} /$ day of insulin is given to the patients undergoing general surgery, in divided doses; as $40-50 \%$ basal insulin and the remainder in pre-meal boluses and this regimen is found to be superior to sliding scale insulin (SSI) (27). SSI regimen is based on; not initiating insulin treatment until a predefined glucose value is exceeded. This method which was popular in seventies lost its importance by the introduction of new and superior methods for glycemic control. However it is still used in some institutions in a "non-evidence based" fashion $(28,29)$.

In short, withholding sulfonylureas and metformin a day before surgery and giving basal bolus insulin if necessary is suggested for good preoperative glycemic control.

\section{How to control blood glucose intraoperatively?}

Algorithms for perioperative control of blood glucose are variable. A traditional approach was to infuse insulin glucose and potassium named shortly as GIK (or Alberti regimen) (30).

Braithwaite algorithm uses a nurse implemented insulin infusion protocol guided by a standardized table which shows the rate of insulin infusion at a given blood glucose value (31). In this approach, 100IU insulin in $100 \mathrm{~mL} 0.09 \% \mathrm{NaCl}$ is infused together with 100-200mL/hour 5\% Dextrose in water $\left(\mathrm{D}_{5} \mathrm{~W}\right)$. There are small studies showing the effectiveness of this approach $(32,33)$.

Recently, variable rate intravenous insulin infusion is used to control blood glucose in the perioperative setting. In this approach, insulin is infused separately, ideally through an electronic infusion pump. This allows tight glycemic control and provides flexibility to the physician in changing doses (20).

United Kingdom guidelines advise implementing variable rate insulin infusion if glycemic control of the patient is not well. The authors suggest using $0.45 \%$ sodium chloride and $5 \%$ glucose with either 0.15 or $0.3 \%$ potassium chloride (as appropriate) as the substrate fluid of choice (20) together with insulin. Hourly measurement of capillary blood glucose to guide insulin infusion rate is recommended by the committee.

Studies looking into the intraoperative management of glucose are few. In a study, which looked into the association of intraoperative glucose values with predefined end points of death, infection, cardiac, neurological, renal, or pulmonary problems; every $20 \mathrm{mg} / \mathrm{dl}$ increase in glucose above $100 \mathrm{mg} / \mathrm{dl}$ was found to be associated with a $34 \%$ increase in experiencing a primary endpoint (34). A multivariate analysis in both diabetic and non-diabetic patients undergoing cardiac surgery showed that a high glucose level during the operation is an independent predictor of mortality in both groups (35). In another study, in which the effect of intraoperative glycemic control on cardiac bypass patients were evaluated, intraoperative insulin infusion was started if blood glucose exceeded $180 \mathrm{mg} / \mathrm{dl}$ and infusion rate was adjusted according to the Portland protocol. Patients whose blood glucose exceeded $200 \mathrm{mg} / \mathrm{dl}$ four times consecutively are defined as poor control group. The authors reported increased risk for severe postoperative complications in patients with poor glycemic control (36). Kohl et al, searched for the effect of intraoperative insulin infusion in to patients undergoing cardiopulmonary bypass surgery. They found a small but beneficial effect of insulin infusion on 30 day mortality in their study in which intraoperative insulin infusion was given to keep blood glucose $<150 \mathrm{mg} / \mathrm{dL}$ by the help of a standard protocol (37).

Administration of insulin glargine with dextrose solution for intraoperative glycemic control is tried in a small study and is found to be no different than GIK infusion (38). However changes in tissue perfusion and body temperature under anesthesia may result in unexpected variations in absorption of subcutaneous insulin. Indeed, insulin infusion is shown to be superior to subcutaneous injections in perioperative period in vascular surgery patients, regarding all cause death, myocardial infarction and congestive heart failure (39). Insulin infusion also 
seems to decrease sternal wound infection and mortality in coronary artery bypass patients $(40,41)$.

\section{Target blood glucose values}

The study by van Den Bergh et al was a landmark in diabetes care (42). This was a prospective randomized controlled study conducted in the surgical intensive care unit (ICU). A total of 1548 patients were enrolled in the study. The patients were grouped as intensive (target blood glucose: $80-110 \mathrm{mg} / \mathrm{dL}$ ) and conventional (insulin started if only blood glucose exceeds $215 \mathrm{mg} / \mathrm{dL}$ and target blood glucose 180-200 $\mathrm{mg} / \mathrm{dL}$ ) treatment groups. At 12 months mortality rate was significantly lower in intensive group than in conventional group $(4.6 \%$ vs $8 \%$ respectively). However this exciting mortality benefit was not repeated in a study carried out by the same investigators in medical ICU setting (43).

Intensive insulin therapy is further questioned when the results of NICE SUGAR study are reported. In this multicenter study, 6104 patients from medical and surgical ICU were randomized to strict (81$108 \mathrm{mg} / \mathrm{dL})$ and conventional (144-180mg/dL) glucose control groups. Mortality was higher in intensive group than in the conventional group $(27.5 \%$ vs $24.9 \%$ respectively, odds ratio for intensive control, 1.14; $95 \%$ confidence interval, 1.02 to $1.28 ; \mathrm{P}=0.02$ ) Increased incidence of hypoglycemia might have contributed to increased perioperative morbidity and mortality.

A meta-analysis of five studies comparing intensive and conventional insulin regimens found similar mortalities in both groups (44). Three of these trials failed to show a mortality benefit of intensive insulin treatment (target blood glucose: $70-179 \mathrm{mg} / \mathrm{dL}$ ) where insulin was begun before, during, or immediately after surgery and was continued for less than 24 hours after surgery. Due to these conflicting data, guidelines about perioperative management of diabetes state different target blood glucose values. European Society of Cardiology (ESC) guidelines rely on the results of NICE SUGAR study and advice a target of $144 \mathrm{mg} / \mathrm{dL}$ in ICU setting (45). American College of Physicians suggests keeping blood glucose between $140-200 \mathrm{mg} / \mathrm{dL}$ in diabetic patients in surgical ICU (46). On the other hand, United Kingdom guidelines define a target glucose of $6-10 \mathrm{mmol} / \mathrm{L}$ (108-180mg/dL) for the diabetic patient undergoing surgery (20).

\section{Postoperative care of diabetic patient}

After the operation, the patient's oral antidiabetics may be restarted, as soon as he/she is able to eat regular meals. For the patients on intravenous insulin infusion, basal bolus insulin regimen may be given postoperatively (47). Total daily dose can be estimated according to the total insulin dose infused in the preceeding 6-8 hours.
About half of the calculated dose may be given as basal insulin and the remainder may be divided into three to be given before meals as short acting insulin. If regular insulin is given as a short acting insulin, insulin infusion should not be stopped for 1-2 hours after the first dose to cover the period between the time of subcutaneous injection of bolus and its initiation of action. A summary of insulin types and their properties is given in table 2 (48). Management of patients in ICU is beyond the scope of this review and the reader may see other reviews discussing this subject (49).

Table 2. Insulin types and their properties

\begin{tabular}{lccc}
\hline $\begin{array}{c}\text { Insulin } \\
\text { type }\end{array}$ & $\begin{array}{c}\text { Onset of } \\
\text { action }\end{array}$ & $\begin{array}{c}\text { Peak } \\
\text { effect }\end{array}$ & $\begin{array}{c}\text { Duration } \\
\text { of action }\end{array}$ \\
\hline Regular & $30-60 \mathrm{~min}$ & $2 \mathrm{~h}$ & $6-8 \mathrm{~h}$ \\
Lispro & $5-15 \mathrm{~min}$ & $60-90 \mathrm{~min}$ & $3-4 \mathrm{~h}$ \\
Aspart & $5-15 \mathrm{~min}$ & $60-90 \mathrm{~min}$ & $3-4 \mathrm{~h}$ \\
Glulysine & $5-15 \mathrm{~min}$ & $60-90 \mathrm{~min}$ & $3-4 \mathrm{~h}$ \\
NPH & $2-4 \mathrm{~h}$ & $6-7 \mathrm{~h}$ & $10-20 \mathrm{~h}$ \\
Glargine & $1,5 \mathrm{~h}$ & Peakless & $24 \mathrm{~h}$ \\
Detemir & $1 \mathrm{~h}$ & Peakless & $17 \mathrm{~h}$ \\
\hline
\end{tabular}

\section{Conclusion}

Proper management of diabetes in the perioperative setting is essential as effect of glycemic control on perioperative morbidity and mortality is well known. Treatment protocols must be tailored individually but evidence based approach in insulin administration and close monitoring of blood glucose are important in order to avoid both hyper and hypoglycemia. Further studies are needed to ascertain target blood glucose values in different surgical patients.

\section{References}

1. http:// euro.who.int/en/what-we-do/healthtopics/noncommunicablediseases/_diabetes/data-andstatistics

2. Girard M, Schricker T. Perioperative glucose control: living in uncertain times--Continuing Professional Development. Can J Anaesth. 2011 Mar;58(3):312-20,320-9

3. Bochicchio GV, Sung J, Joshi M, et al. Persistent hyperglycemia is predictive of outcome in critically ill trauma patients. J Trauma 2005; 58: 921-4 51

4. Bochicchio GV, Salzano L, Joshi M, Bochicchio K, Scalea TM. Admission preoperative glucose is predictive of morbidity and mortality in trauma patients who require immediate operative intervention. Am Surg 2005; 71: 171-4

5. Kerby JD, Griffin RL, MacLennan P, Rue LW. Stressinduced hyperglycemia, not diabetic hyperglycemia, is associated with higher mortality in trauma. Ann Surg 2012; 256: 446-52

6. Dhatariya K, Levy N, Kilvert A, et al. NHS diabetes guideline for the perioperative management of the adult patient with diabetes. Diabet Med 2012; 29: 420-33 
7. Carson JL, Scholz PM, Chen AY, Peterson ED, Gold J, Schneider SH. Diabetes mellitus increases short-term mortality and morbidity in patients undergoing coronary artery bypass graft surgery. J Am Coll Cardiol 2002; 40: 418-23

8. Szabo Z, Hakanson E, Svedjeholm R. Early postoperative outcome and medium-term survival in 540 diabetic and 2239 nondiabetic patients undergoing coronary artery bypass grafting. Ann Thorac Surg 2002; 74: 712-9

9. Schuster JM, Rechtine G, Norvell DC, Dettori JR. The influence of perioperative risk factors and therapeutic interventions on infection rates after spine surgery: a systematic review. Spine (Phila Pa 1976). 2010 Apr 20;35(9 Suppl):S125-37

10. GodoyDA, Di Napoli M, Biestro A, Lenhardt R Perioperative glucose control in neurosurgical patients Anesthesiol Res Pract 2012; 2012: 690362

11. Milaskiewicz RM, Hall GM. Diabetes and anaesthesia: the past decade. Br J Anaesth 1992; 68: 198-206

12. http://circ.ahajournals.org/content/early/2014/07/31/CIR. 0000000000000105.citation

13. American Diabetes Association. Standards of medical care in diabetes - 2013. Diabetes Care 2013; 36 (Suppl. 1): S1166

14. Abdelmalak B,AbdelmalakJB, Knittel J, et al.Theprevalenceof undiagnosed diabetes in non-cardiac surgery patients, an observational study. Can J Anaesth 2010; 57: 1058-64

15. Lauruschkat AH, Arnrich B, Albert AA, et al. Prevalence and risks of undiagnosed diabetes mellitus in patients undergoing coronary artery bypass grafting. Circulation 2005; 112: 2397-402

16. Kohl BA, Schwartz S. How to manage perioperative endocrine insufficiency. Anesthesiol Clin 2010; 28: 139-55

17. Sato H, Carvalho G, Sato T, Lattermann R,MatsukawaT, Schricker T. The association of preoperative glycemic control, intraoperative insulin sensitivity, and outcomes after cardiac surgery. J Clin Endocrinol Metab 2010; 95: $4338-44$

18. Han HS, Kang SB. Relations between long-term glycemic control and postoperative wound and infectious complications after total knee arthroplasty in type 2 diabetics. Clin Orthoped Surg 2013; 5: 118-23

19. Sebranek,A. Kopp Lugli, D. B. Coursin. Glycaemic control in the perioperative period. British Journal of Anaesthesia 2013; 111 (S1): i18-i34

20. Dhatariya K, Levy N, Kilvert A, Watson B, Cousins D, Flanagan D, Hilton L, Jairam C, Leyden K, Lipp A, Lobo D, Sinclair-Hammersley M, Rayman G; Joint British Diabetes Societies. NHS Diabetes guideline for the perioperative management of the adult patient with diabetes. Diabet Med. 2012 Apr;29(4):420-33

21. Dell'aquila A, Ellger B. perioperative glycemic control ; what is worth the effort. Curr Opin Anesthesiol 2013, $26: 438-443$

22. Duncan AE.Hyperglycemia and perioperative glucose management Curr Pharm Des. 2012 ; 18(38): 6195-6203
23. Gu W, Pagel PS, Warltier DC, Kersten JR. Modifying cardiovascular risk in diabetes mellitus. Anesthesiology. 2003; 98:774-9

24. Bailey CJ, Turner RC. Drug therapy: Metformin. N Engl J Med. 1996; 334(9):574-9.

25. Duncan AE. Hyperglycemia and perioperative glucose management. Curr Pharm Des. 2012;18(38):6195-203

26. Houlden R, Capes S, Clement M, Miller D. Canadian Diabetes Association Clinical Practice Guidelines Expert Committee. In-hospital management of diabetes. Can J Diabetes. 2013 Apr;37 Suppl 1:S77-81.

27. Umpierrez GE, Smiley D, Jacobs S, et al. Randomized study of basal-bolus insulin therapy in the inpatient management of patients with type 2 diabetes undergoing general surgery (RABBIT 2 surgery). Diabetes Care 2011;34:256

28. Umpierrez G, Maynard G. Glycemic chaos (not glycemic control) still the rule for inpatient care: how do we stop the insanity? J Hosp Med 2006;1:141.

29. Umpierrez GE, Palacio A, Smiley D. Sliding scale insulin use: myth or insanity? Am J Med 2007;120:563

30. Thomas DJ, Platt HS, Alberti KG. Insulin-dependent diabetes during the peri-operative period. An assessment of continuous glucose- insulin-potassium infusion, and traditional treatment. Anaesthesia 1984; 39: 629-637

31. Trence DL, Kelly JL, Hirsch IB. The rationale and management of hyperglycemia for in-patients with cardiovascular disease: time for change. J Clin Endocrinol Metab. 2003 Jun;88(6):2430-7

32. Markovitz LJ, Wiechmann RJ, Harris N, Hayden V, Cooper J, Johnson G, Harelstad R, Calkins L, Braithwaite SS. Description and evaluation of a glycemic management protocol for patients with diabetes undergoing heart surgery. Endocr Pract. 2002 Jan-Feb;8(1):10-8

33. Emam IA, Allan A, Eskander K, Dhanraj K, Farag el-S, E1Kadi Y, Khalaf W, Riad SR, Somia R. Our experience of controlling diabetes in the peri-operative period of patients who underwent cardiac surgery. Diabetes Res Clin Pract. 2010 Jun;88(3):242-6

34. Gandhi GY, Nuttall GA, Abel MD, et al. Intraoperative hyperglycemia and perioperative outcomes in cardiac surgery patients. Mayo Clin Proc 2005; 80: 862-6

35. Doenst T,Wijeysundera D, Karkouti K, et al. Hyperglycemia during cardiopulmonary bypass is an independent risk factor for mortality in patients undergoing cardiac surgery. J Thorac Cardiovasc Surg 2005; 130: 1144

36. Ouattara A, Lecomte P, Le Manach Y, Landi M, Jacqueminet S, Platonov I, Bonnet N, Riou B, Coriat P. Poor intraoperative blood glucose control is associated with a worsened hospital outcome after cardiac surgery in diabetic patients. Anesthesiology. 2005 Oct;103(4):687-94

37. Kohl BA, Hammond MS, Ochroch EA. Implementation of an intraoperative glycemic control protocol for cardiac surgery in a high-acuity academic medical center: an observational study. J Clin Anesth. 2013 Mar;25(2):121-8

38. Kang H, Ahn KJ, Choi JY, Park HJ, Park SJ, Lee SK. Efficacy of insulin glargine in perioperative glucose control in type 2 diabetic patients. Eur J Anaesthesiol. 2009 Aug;26(8):666-70. 
39. Subramaniam B, Panzica PJ, Novack V, et al. Continuous perioperative insülin infusion decreases major cardiovascular events in patients undergoing vascular surgery: a prospective, randomized trial. Anesthesiology 2009; 110:970-977

40. Gandhi GY, Nuttall GA, Abel MD, Mullany CJ, Schaff HV, O'Brien PC, Johnson MG,Williams AR, Cutshall SM, Mundy LM, Rizza RA, McMahon MM. Intensive intraoperative insulin therapy versus conventional glucose management during cardiac surgery: a randomized trial. Ann Intern Med. 2007 Feb 20;146(4):233-43

41. Furnary AP, Zerr KJ, Grunkemeier GL, Starr A. Continuous intravenous insülin infusion reduces the incidence of deep sternal wound infection in diabetic patients after cardiac surgical procedures. Ann Thorac Surg. 1999 Feb;67(2):35260

42. Van den Berghe G, Wouters P, Weekers F, Verwaest C, Bruyninckx F, Schetz M,et al. Intensive insulin therapy in the critically ill patients. N Engl J Med. 2001; 345:1359-67

43. Van den Berghe G, Wilmer A, Hermans G, Meersseman W, Wouters PJ, Milants I, Van Wijngaerden E, Bobbaers H, Bouillon R. Intensive insulin therapy in the medical ICU. N Engl J Med. 2006 Feb 2;354(5):449-61

44. Hua J, Chen G, Li H, et al. Intensive intraoperative insulin therapy versus conventional insulin therapy during cardiac surgery: a meta-analysis. J Cardiothorac Vasc Anesth 2012; 26: 829-34
45. Poldermans D, Bax JJ, Boersma E, De Hert S, Eeckhout E, Fowkes G, Gorenek B, Hennerici MG, Iung B, Kelm M, Kjeldsen KP, Kristensen SD, Lopez-Sendon J, Pelosi P, Philippe F, Pierard L, Ponikowski P, Schmid JP, Sellevold OF, Sicari R, Van den Berghe G, Vermassen F. European Society of Cardiology (ESC). Guidelines for pre-operative cardiac risk assessment and perioperative cardiac management in non-cardiac surgery. Eur Heart J. 2009 Nov;30(22):2769-812

46. Qaseem A, Humphrey LL, Chou R, Snow V, Shekelle P; Clinical Guidelines Committee of the American College of Physicians. Use of intensive insulin therapy for the management of glycemic control in hospitalized patients: a clinical practice guideline from the American College of Physicians. Ann Intern Med. 2011 Feb 15;154(4):260-7

47. Schmeltz LR, DeSantis AJ, Schmidt K, et al. Conversion of intravenous insülin infusions to subcutaneously administered insulin glargine in patients with hyperglycemia. Endocr Pract 2006;12:641e50

48. Masharani U, German MS. Pancreatic Hormones and diabetes mellitus. In:Gardner DG, Shoback D,ed. Greenspans Basciand Clinical Endocrinology $9^{\text {th }}$ ed. McGraw Hill 2011:573-655

49. Abdelmalak BB, Lansang MC. Revisiting tight glycemic control in perioperative and critically ill patients: when one size may not fit all. J Clin Anesth. 2013 Sep;25(6):499-507

Copyright $(0) 2014$ The Author(s); This is an open-access article distributed under the terms of the Creative Commons Attribution License (http://creativecommons.org/licenses/by/4.0), which permits unrestricted use, distribution, and reproduction in any medium, provided the original work is properly cited. 